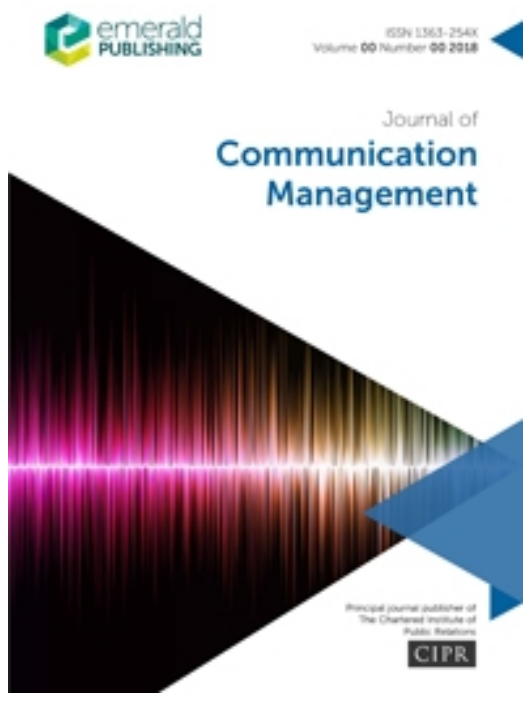

\title{
Investigating the Role of Contextual Factors in Effectively Executing Communication Evaluation and Measurement: A Scoping Review
}

\begin{tabular}{|r|l|}
\hline Journal: & Journal of Communication Management \\
\hline Manuscript ID & JCOM-12-2018-0131.R3 \\
\hline Manuscript Type: & Original Article \\
\hline Keywords: & $\begin{array}{l}\text { Evaluation, Measurement, Organisational performance, Organisational } \\
\text { effectiveness }\end{array}$ \\
\hline \multicolumn{2}{|l}{} \\
\hline
\end{tabular}




\section{Investigating the Role of Contextual Factors in Effectively Executing Communication Evaluation and Measurement: A Scoping Review}

\section{Abstract}

Purpose. Evaluation and Measurement (E\&M) remains a critical and debated topic among communication scholars and practice. Substantial research and professional efforts have been devoted to discussing what should be measured and which methods should be applied. Most of the E\&M models seem to carry a positivist imprint. But, in real-life, organizations could not have clear aims, enough resources, or adequate informative systems to support E\&M. Moreover, several contextual factors could affect the implementation of E\&M management processes. The communication literature rarely highlights these factors. To fulfill this gap, the following article aims at theorizing the contextual factors relevant to the management of the evaluation process.

Design. A scoping literature review was carried out exploring the role of contextual factors and impact of contextual factors on E\&M management processes. More specifically, the review examines the contribution provided by program evaluation and performance measurement fields of research.

Findings. The findings of the scoping review explain how both streams of thought argued the importance of contextual factors, such as organizational, relational, cultural, and communicative factors, for the success of any evaluation processes. The review underlined that the main evaluation models used in the field of communication have overlooked these studies and put on evidence the role of contextual factors in effectively executing communication evaluation and measurement.

Originality. The paper enriches the dominant rationale concerning the E\&M management processes by incorporating literature on a) program evaluation and 2) performance measurement. The analysis could provide useful insights also from a professional perspective, by helping practitioners for a contextual assessment of strategic communication programs and activities.

Keywords: Situational evaluation, performance measurement, contextual factors, program evaluation 


\section{INTRODUCTION}

Since the 1960s, evaluation and measurement (E\&M) remains a critical and much debated topic among communication scholars. Substantial research and professional effort have been devoted to discussing what should be measured and which methods should be applied.

Focusing on these questions is crucial, but in the meantime, it assumes that the effectiveness of E\&M models' design and their successful execution mostly depend on the choice of the right metrics and research methods. In fact, most of the E\&M models and frameworks seem to carry a positivist imprint, by conceptualizing communication programs as rational actions based on the program logic methodology objectives-means(inputs)-outputs-outcomesimpacts. This positivist rationale also implies that individuals operate with a goal-oriented, planning-focused, and information-driven culture within their organizations. Contra to this supposition, in real-life organizations often do not have clear aims, adequate resources, or adequate information systems to support E\&M processes.

E\&M processes can follow non-linear and uncertain paths in response to contextual factors (Pawson and Tilley, 1997; Swenson et al., 2019). E\&M processes can be very challenging, requiring a complex blend of elements, which may at times demand the resolution of conflicting needs. Morgan (2007), for instance, describes E\&M as political processes, characterized by political alliances, bargaining, conflicts and compromises. Baskin and Aronoff (1988), for instance, analysed open and closed system evaluation, by recognizing and examining the role of factors outside the control of communication which could affect public relations' program results.

The influence of context in the E\&M processes has been included in some of the models and frameworks more recently developed by communication scholars - for example, the integrated evaluation framework by AMEC (AMEC, 2017) and the Integrated Evaluation Model by Macnamara (2018). Nevertheless, the communication literature has largely 
overlooked these influential contextual factors. The debate so far has been focused on identifying barriers preventing the advancement in E\&M implementation (Swenson et al., 2019). Much scholarship has explored the impact of the expertise and role of Chief Communication Officers (CCOs) within successful measurement programs, but it underestimates the role of organizational context (Swenson et al., 2019).

In this conceptual article we argue that a plethora of contextual factors, such as for instance, concerned parties' expectations or evaluative management styles, could affect the implementation of any E\&M process. More specifically, this article aims at theorizing the contextual factors relevant to the management of the evaluation process. This paper explores those factors which need to be taken into account to effectively support initial and ongoing E\&M implementation within the communication area.

The paper enriches the dominant extant academic debate concerning the E\&M process in two ways. Firstly, it provides a scoping literature review of the theoretical underpinnings of performance measurement and program evaluation research, which helps close an identified research gap in communication literature. Despite the differences between the two approaches, they are complementary ways of acquiring and analysing information that is intended to reduce uncertainty around programs (McDavid and Hawthorn, 2006). These streams of thought underline a new research problem, namely, how to effectively implement and execute an E\&M system. Secondly, it proposes a categorization schema for the factors shaping the E\&M models' implementation.

In order to achieve its aim, this article is structured as it follows. The first part provides the results of a scoping literature review focused on the extant communication E\&M models and identifies how both program evaluation and performance measurement streams of thought argue the importance of contextual factors, such as organizational, relational, cultural, and communicative factors, in the success of any evaluation process. 
In the second part, insights from program evaluation and performance measurement fields of research are combined and discussed and insights are developed for a contextual assessment of strategic communication E\&M programs and activities. Finally, limitations and future applications are discussed in the conclusive section.

\section{LITERATURE REVIEW}

Communication studies have shown that in the design phase of communication programs the most fruitful approach might combine evaluation and measurement methodologies, by highlighting their complementary role (McDavid and Hawthorn, 2006; McDavid et al., 2012). On the one hand, evaluation consists of systematic collection, analysis and interpretation of data and information concerning activities under scrutiny, in order to pass judgment on their functioning as well as to guide further decisions and actions for all the involved actors (Patton, 1998; Rossi et al., 2003). On the other hand, "measurement is the process of translating constructs into procedures for collecting data" (McDavid and Hawthorn, 2006, p. 159). Combining evaluation and measurement within a single research design represents something more than a mere methodological exercise. It calls for a union between two divergent scientific domains: program evaluation and performance measurement. Since the 1960s, the communication literature largely has borrowed concepts, techniques, and methodologies from these two scientific domains. Among the inherited concepts, in both approaches, a certain weight has been given to the context within which E\&M processes are embedded. For this reason, the paper provides a scoping review (Rumrill et al., 2010) of the two different scientific domains of program evaluation and performance measurement.

As pointed out by Macnamara and Likely (2017), program evaluation is based on the assessment of "how programs can be designed and implemented to achieve their objectives" (p. 9), while performance measurement is based on measuring program outputs and outcomes, 
without trying to recognize the extent to which the program has affected the outcomes (Nielsen et al., 2013). Despite differences, both approaches provide useful insights concerning the role of contextual factors in the effectiveness of E\&M management processes.

A scoping literature review is a useful method to synthesize research findings embedded in diverse disciplinary areas and to identify potential gaps in the research literature (Arksey and O’Malley, 2005; Rumrill et al., 2010). This paper follows the procedures discussed by Arksey and O'Malley (2005) and illustrated by Rumrill et al. (2015) that can be summarized as it follows: a) identify the initial research questions; b) identify the relevant studies; c) refine the inclusion and/or exclusion criteria for selecting studies; d) organize data to represent the descriptive elements of the scoping review; e) provide a narrative description for reporting results.

The paper is framed around the following research questions:

RQ1. What is the contribution provided by program evaluation and performance measurement fields of research concerning the role and impact of contextual factors on E\&M management processes?

RQ2. Which insights can be drawn with regard to contextual factors influencing the execution of communication E\&M management processes?

In order to answer these research questions, a search of the literature was performed across the EBSCO - Academic Search Complete database. The paper takes into consideration relevant studies and research conducted in the program evaluation and performance measurement fields. Review includes studies which investigate and evidence the role of internal contextual factors in $\mathrm{E} \& \mathrm{M}$ management processes. In anticipation of the findings, the identified literatures focused on internal contextual factors that could drive how evaluation is undertaken: evaluation questions and measures; evaluation approach and design; role of the evaluator and role of 
stakeholders; evaluative culture; final reports; information technology support and use of results.

The following sections provide a narrative description of the scoping review and they address three main cluster of results: first, an analysis of the state of the art of communication E\&M research; second, the contributions published in the program evaluation domain; third, analysis of studies and research in the performance measurement research area.

\section{Communication E\&M Research}

The growing relevance of E\&M as a strategic activity for communication professionals has given rise to a considerable amount of research during the last 40 years (Watson and Likely, 2013; Volk, 2016; Zerfass et al., 2017; Macnamara, 2018a, 2018b).

A wide range of studies has underlined a number of common concepts that underlie E\&M processes. For instance, multiple purposes can be fulfilled through E\&M, primarily, formative and summative (Scriven, 1996; Macanamara, 1999). For formative purposes, E\&M help to optimize the financial resources allocated to communication activities or help to improve and prioritize communication strategies. For summative purposes, E\&M processes can assist communication managers in obtaining internal legitimacy by making communication value more explicit and the results clearly beneficial in the eyes of the entire organization.

The importance of goal setting is an additional element common to E\&M models to date. For instance, among the earliest models, the Short and The Continuing Model of Evaluation by Watson (2001) attributed a close relationship between the definition of communication objectives and the choice of a specific evaluation model. Setting down clear and specific objectives is also the first of the 10 Barcelona principles, a declaration set down in 2010, revised in 2015 (AMEC, 2015) and agreed by more than 200 professionals from across the world. 
Communication scholars have also adopted a multi-level approach which identifies the stages of E\&M. Hence, the concept of the "logic model" has gained predominance (Julian, 1997). Logic models assume that inputs feed activities and in turn generate outputs, outcomes and impacts. Many communication frameworks follow the logic model approach to define the stages of E\&M (i.e. outputs, outcomes and impacts) such as, for instance, the Yardstick Model (Lindenmann, 1997), the Preparation, Implementation and Impact (PII) model (Cutlip et al., 2000) and the Macro Model of PR Evaluation (Macnamara, 1997), the GCS Evaluation Framework (GCS, 2016), the AMEC integrated evaluation framework (AMEC, 2017) and the Integrated Evaluation Model (Macnamara, 2015, 2018). The main assumption underlying such frameworks is that the choice of metrics matters. Communication evaluators should replicate the logic model's stages and identify proper metrics at each level. Other frameworks, such as the Communication Balanced Scorecard (Fleisher and Mahaffy, 1997; Ritter, 2003; Vos, Schoemaker, 2004; Zerfass, 2010), share the same basic assumption and offer a set of communication performance metrics which acknowledge a closer link between value created by communication activities and firm's goals.

Communication E\&M models put a great emphasis on the methodological rigour and the use of research methods and techniques to collect valid and reliable results. To this end, traditionally quantitative research methods are given priority over qualitative ones, because collecting quantitative data seems to provide a more objective approach to reality (Daymon and Holloway, 2010). This way of examining reality emphasises unbiased assessment. Reality is seen as an entity that can be observed irrespective of the individuals who experience it, so factors are set aside from their natural context for measurement purposes (Morgan, 2007). In distinction to this, qualitative methods are characterized by an interpretative approach to the analysis of social reality: they take into account and explore the intentions, motivations and experiences of all involved actors (Daymon and Holloway, 2010; Grunig et al., 2002). For this 
reason, qualitative methods highlight the relational dimension of the communication process. It is helpful to gain basic knowledge of unusual phenomena and provide some interpretations of them (Ritchie, 2003).

Using different approaches enables practitioners to describe, foresee and control the totality of the communication process. An effective evaluation model does not limit the use of qualitative methods to the experimentation stage, but merges them with quantitative ones to exploit the benefit of both (Daymon and Holloway, 2010).

One of the first evaluation models that underlines the role of contextual factors for implementing an E\&M process is the Measurement Tree model, elaborated in 2003 by the Institute of Public Relations. The measurement model is graphically represented as a tree. The roots are the communication objectives. The trunk stands for communication strategies and tactics. The bark covering the trunk represents services, products and other company aspects, which are made public. The sap going through the trunk embodies all those elements of communication that can only be accessed by staff and employees. Branches refer to the target audience, leaves are related to the public for which media relations plans are designed, and flowers represent outcomes - all the changes in opinions, attitudes, and behaviours that communication has produced in target audiences (Jin and Cameron, 2007). Finally, the tree is planted into a natural environment, which refers to the market the organization operates in and the organizational climate where the communication plan has been implemented. The Measurement Tree model is one of the early evaluation models which take account of the organizational context and the external environment and considers them as factors influencing results. Nevertheless, the Measurement Tree model does not help communicators deepen their understanding of which specific environmental factors can impact the implementation of E\&M management processes; it provides just a generic outline of the environment in which they are embedded. 
Other recent and well-known models, such as the GCS Evaluation Framework (GCS, 2016), the AMEC integrated evaluation framework (AMEC, 2017) and the Integrated Evaluation Model (Macnamara, 2018), value both internal and external organizational contexts where the E\&M management processes take place and recognise this can affect their design, but they do not investigate in detail the nature of these factors.

Overall, current studies focused on E\&M management processes and their implementation in the communication field lack a detailed analysis of those contextual factors affecting execution of E\&M processes that could be organizational, relational, cultural and communicative. By reviewing the research in the fields of program evaluation and performance measurement these contextual factors can be identified and categorized.

\section{Program Evaluation Research}

The conceptual roots of most communication E\&M models lie within the expanded domain of program evaluation, which places special emphasis on the application of social research methods to address evaluation questions and formulate sound judgements (Fitzpatrick et al., 2004). The origin of the scholarly inquiry on evaluation research can be traced back to the end of the 1950s. Evaluation research, or program evaluation, can be defined as "a social science activity directed at collecting, analyzing, interpreting and communicating information about the workings and effectiveness of social programs" (Rossi et al., 2003, p. 2). Social programs are designed to ameliorate a social problem (i.e. delinquency prevention programs) or improve social conditions (i.e. public housing programs), in specific areas such as public health, welfare and education.

Until the 1980s, evaluation research theory focused attention on the distance between the actual inputs and the expected impacts of a programme, the so-called "black box". Since the main purpose of program evaluation consists of understanding how much of the observed 
impacts of a program could be attributed to the invested inputs, the experimental technique has always been considered as the research design par excellence (Cooper et al., 2006). In experimental studies, both the internal validity (causality links among inputs and outcomes) and the external validity (generalization of results) of a program are the main concerns. By definition, using an experimental design means to implicitly assume that every program occurs in a vacuum. In other words, nothing, with the exception of inputs, can affect the expected outcomes and impacts of a programme.

Since the 1980s, so-called theory-based approaches challenged these assumptions by positing that black boxes should have been opened and by arguing that evaluation practices should have been aimed at examining the interrelationships among inputs, outputs and outcomes (Weiss, 1997). The relevant literature on Theory-Based Evaluation (TBE) between 1980 and 1990 yielded a new wave of "opened black boxes" approaches. The conceptual rationale underlying TBE is based on the notion of "bounded rationality", which can be defined as "the limits upon the ability of human beings to adapt optimally, or even satisfactorily, to complex environments" (Simon, 1991, p. 132). Therefore, programs could function completely differently from being intended, since outcomes and impacts will depend on how the mechanisms that are supposed to be at work within a program, will be enacted in a given context. Most of the evaluation models assume that individuals operate with a goal-oriented, planning-focused, and information-driven culture within their organizations. But, in real-life situations people experience quite different situations.

Thus, evaluators should be aware of the contextual factors affecting the outcomes and impacts of a program, for instance, concerned parties' expectations are crucial to inhibiting impacts from happening or enabling a program to produce intended results. According to TBE, evaluators must take into account the legitimate concerns of those individuals who can affect (or be affected by) evaluation's results (Pawson and Tilley, 1997; Scriven, 1996). This 
means evaluators need to be aware of possible evaluation questions that could arise from stakeholder interests during the communication program and which may impact on the measures that have to be taken into account in evaluation.

Pawson and Tilley (1997) argue that the principal goal of evaluation research is to understand what works best, for whom, in what circumstances, and why. Hence, theories, not methods, should be put at the centre of any evaluation design and implementation. No method is seen as the single gold standard, but TBE approaches combine all methods that could be suitable without privileging any one of them. TBE reflected the importance of addressing the needs of those who have an interest in the evaluation process (Scriven, 1996).

Other scholars are primarily concerned with the methodological aspects of evaluation and more specifically the evaluation approach and design (Weiss and Bucuvalas, 1980;

Fetterman et al., 1996) and argue that priority should be accorded to information holders, who ensure the timely collection of reliable data.

Morgan (2007) states that evaluation aims could be affected by eventual compromises developed between competing coalitions. Sometimes aims could appear ambiguous and weak in an attempt to satisfy stakeholders with different needs. Here, Morgan's vision (2007) of how assessment processes take place within organizations appears realistic and concrete. The author claims a "pragmatic approach", as a new paradigm leading social research methods, which emphasizes the relevance of shared meaning and joint actions in evaluation management processes. As Morgan (2017) argues "the essential emphasis is on actual behavior ("lines of action"), the beliefs that stand behind those behaviors ("warranted assertions"), and the consequences that are likely to follow from different behaviors ("workability")" (p. 67).

Rossi et al. (2003) use the concept of "social ecology of evaluation" to address the social arena where evaluations are implemented, since organizational members' attitudes towards evaluation could vary. Referring to this practice, additional contextual factors are again related 
to the role of stakeholders involved in the program evaluation process and to the role of evaluators themselves (Fetterman et al., 1996; Ask et al., 2012; Patton, 1998).

Fetterman et al. (1996) address the concept of Empowerment Evaluation, "an approach to gathering, analyzing, and using data about a program and its outcomes that actively involves key stakeholders in all aspects of the evaluation process" (p. 814). The rationale underlying this perspective lies in the crucial role of collective and collaborative interpretation, discussion and reflection on evaluation findings. The more closely stakeholders are engaged, the more likely they are to use results to improve their work.

Over the last few years, constructivist approaches to evaluation which enhance engagement have acquired more relevance, such as, for example, participatory, collaborative, and empowerment evaluations (Askew et al., 2012).

Since evaluation processes refer to multiple stakeholders, the aspiration of satisfying all stakeholders' expectations appears unrealistic and so the evaluator's role can be seen as making decisions about the order and priority of stakeholders. Taking a utilization-focused evaluation approach, Patton (1998) points out that evaluation should provide strategic support to decision-making processes and therefore the final users of results are given more priority among stakeholders.

Turning to the role of evaluators, this can be affected by the evaluative culture (Julian, 1997; Jackson, 2013; Mayne, 2008). According to TBE, logic models can be most useful when integrated with the theory of change. Logic models are concerned with how programs ideally work, by representing them as sequences of steps from inputs to the final impacts (Julian, 1997) whereas theory of change establishes a clear understanding of how a program actually works. Theory of change refers to "the construction of a model that specifies (usually visually) the underlying logic, assumptions, influences, causal linkages and outcomes of a development program or project" (Jackson, 2013, p. 97). Through the theory of change, 
increasingly it has become clear in TBE studies that the contextual factor of evaluative culture, affected for instance by different management styles, can impact the functioning of a program, and in turn, its effects. In fact, programs are the results of the aggregation of a larger set of assumptions, risks, and contextual factors.

Moreover, any organization features a more or less explicit evaluative culture, which "denotes an organizational culture that deliberately seeks out information on its performance in order to use that information to learn how to better manage and deliver its programmes and services, and thereby improve its performance" (Mayne, 2008, p. 1). According to Mayne (2008) a number of factors foster an evaluative culture: committed organizational leaders, regular communications on results management, a balance between accountability and learning, capacity for results management, supportive structures and policies.

Evidently, an organizational culture focused on quantitative measures and/or economic outputs will encourage professionals to apply strategies assigning an economic value to communication results. Therefore, auditing the evaluative culture is a necessary condition for program evaluation because evaluation itself is a contextual process and is affected by the organizational situation in which it takes place. Auditing the evaluative culture is also important in order to understand the environment in which evaluation will take place and to make changes to solve problems as a result of that environment that might affect the evaluation.

Finally, contextual factors relate to the support of information technology, to the way final reports are created and to using results (McDavid and Hawthorn, 2006; Macnamara, 2014; Macnamara and Likely, 2017; Knowlton and Phillips, 2013).

According to McDavid and Hawthorn (2006), in order to implement an E\&M management process, it is necessary to take into account and establish the multi-channel ways of communicating to facilitate the sharing of information, measurement problem identification, 
and solving. Information technology has to be tailored to the program that needs to be evaluated and final reports and the use of results have to be customized and negotiated by stakeholders. Program evaluation scholars evidence the crucial role of iterative planning that uses results and findings collected at each stage of the program evaluation process in order to adjust strategies and tactics (Macnamara and Likely, 2017). Knowlton and Phillips (2013) for instance depict program evaluation as a cycle characterized by an iterative approach.

\section{Performance measurement research}

At the turn of $21^{\text {th }}$ century in the USA, performance measurement became a critical and much debated issue, since it was connected primarily with financial accountability to measure costs and outputs of governmental programs. Performance measurement can be distinguished from performance management. Performance measurement "provides the basis for an organisation to assess how well it is progressing towards its predetermined objectives, helps to identify areas of strengths and weaknesses, and decides on future initiatives, with the goal of improving organisational performance" (Amaratunga and Baldry, 2002, p. 218). Performance management can be defined as "the use of performance measurement information to effect positive change in organizational culture, systems, and processes by helping to set agreedupon performance goals, allocating and prioritizing resources, informing managers" (Sachs, 2011, p. 58).

As previously discussed, performance measurement and program evaluation are complementary ways of acquiring and analyzing information about a program and they rely on a common core of methodologies (McDavid et al., 2012).

Concerning the contextual factor of evaluation questions and measures, while program evaluation allows users to address questions of why observed programs results occurred, performance measurement is more focussed on cost-effectiveness and describes patterns of 
actual programs and organizational results (McDavid et al., 2012). In other words, performance measurement describes what is going on, but it does not explain why it is happening. Measures usually derive from strategies and are clearly identified and simple to understand and use (Lynch and Cross, 1991; Maskell, 1989; Neely et al., 1996). Similarly, also the evaluation approach and design in the performance measurement literature are considered as a routine to replicate (Neely et al., 2000).

Within the performance measure field, managers play the role of evaluators, that means they determine the main aspects on which program and employee are assessed and they identify the consequences related to the measured performances (Kerssens-van Drongelen and Fisscher, 2003).

Moreover, since the introduction of performance measurement is an important change to the organization's way of doing business, it is important that there are organizational leaders who are considered champions of this in order to provide continuous support to the process and to exert the power of evaluator. However, measurement sometimes increases uncertainty among managers since results are unpredictable and therefore some of them resist the introduction of performance measurement.

Concerning the role of stakeholders, results are shared among them. According to Band (1990), performance measures should have support from management and stimulate engagement among stakeholders in order to create a feedback loop that enriches the interpretation of results.

Over the last 20 years, the performance measurement (PM) literature has moved from considering the structural and technical features of the measurement process to examining contextual factors, such as the evaluative culture and management style, as well as other behavioural aspects (Neely, 2005). Here, context relates to organizational, relational, social and cultural factors that could affect how the measurement process is implemented and how 
measurement results are used to improve organizational performance. When a measurement system is context-sensitive it has reached a high level of maturity: "Maturity, in the context of PM, is defined as the ability to respond to the environment in an appropriate manner through performance measurement \& management practices" (Bititci et al., 2015, p. 25). A positive relationship exists between the maturity of the performance system and the quality of obtained performance. If the measurement system is mature, it is context-optimized, results are used effectively to support managerial routines based on communication, which in turn facilitates informed-decision making and helps to establish an organizational learning culture (Neely, 2005). Scholars also emphasize the role of cultural differences among those involved in evaluation processes which is crucial in shaping attitudes and orientations toward evaluation and measurement (Mattila, 1999; Winstead, 1999). Kravchuk and Schack (1996) suggest that the most appropriate metaphor to build a performance culture is the learning organization by Senge (1990).

In order to learn from results, organizations need to rely on information technology procedures that not only support data collection, but also facilitate the top-down, bottom-up and horizontal sharing of information and help with problem identification and problem solving (Wettstein and Kueng, 2002).

Results obtained through information technology procedures are translated into final reports that are developed through routinized processes (Douwe et al., 1996). The use of such results ideally evolves over time as management guides the performance measurement process (Hatry, 2006).

\section{DISCUSSION}

To draw together what has been explored in the previous section, the following table 1 compares the different roles that contextual factors play within program evaluation and 
performance measurement perspectives. While considering their centrality, each of the two perspectives conceptualizes in a different way the contextual factors in the evaluation process.

[Please insert table 1 here]

\section{Role of contextual factors in program evaluation and performance measurement (RQ1)}

In sum they begin to answer RQ1. Concerning the first two factors in table 1 (evaluation questions \& measures, and evaluation approaches \& designs), program evaluation includes ad hoc, tailor-made, and customized processes taking into account organizational evaluation needs.

Performance measurement refers to routinized and regularized processes, which are performed on an ongoing basis. Program evaluation holds in high regard the criteria used to select measures since they have to be fully aligned to the purposes of the measurement process. With performance measurement the selection of measures takes place on a one-off basis and their collection is seen as a routine practice. According to program evaluation ad hoc measures are identified for each evaluation process. Program evaluation attaches great importance to the fact that the research methods used have to be built on sound scientific grounds in order to ensure the replicability of the evaluation process. However, scientific approaches entail methodological skills, longer implementation time, and more resources. Concerning the second set of factors (role of evaluator, role of stakeholders, and evaluative culture), the two perspectives have some similarities and differences. In program evaluation, the role of the evaluator is to guarantee the right research design, according to his/her expertise. However, in performance measurement, given the evaluation process is essentially a management activity, the manager plays the role of an evaluator in charge of selecting, 
collecting, and interpreting metrics as well as of strategically managing the whole measurement process.

Identifying stakeholders' expectations of the evaluation and measurement process is crucial. Individuals other than communication managers and technicians might be interested in the evaluation process, so they have to be properly informed and their needs met. Program evaluation identifies stakeholders at the beginning of the process in order to understand their needs and expectations, but in performance measurement, stakeholders are informed about results through periodic reports.

Organizational members' attitudes towards evaluation could vary. All organizations feature a more or less explicit evaluative culture, which includes the set of measures that the management regards as important as well as the goals to be measured through the evaluation (e.g. a tool for punishing or rewarding staff for improved performance). Auditing the evaluative culture is also important to understand the current state of affairs and to make changes to solve any issues that might affect the evaluation. Similarly, performance measurement should be aligned with the managerial systems used by organization otherwise it could create separate information chains and prompt criticism by organizational subjects. Addressing the last group of factors (IT support, final report, and use of results), the communication of results is an essential part of measurement and evaluation processes. How the results are communicated could be different according to the used approach. Within program evaluation, reports are created ad hoc, while in performance measurement, reporting activity is continuous, systematic, and follows standardized procedures. Moreover, in performance measurement, information systems provide data from different sources, which are automatically integrated, elaborated, and systematized in standard reports. The use of information systems is less systematic within program evaluation. 


\section{Influencing contextual factors for E\&M management processes in the communication}

\section{field (RQ2)}

The analysis of the role of contextual factors in program evaluation and performance measurement studies reveals a new research issue which deserves attention: the need to investigate how to effectively implement and execute E\&M management processes and what those contextual factors are which constitute potential sources of strength and weakness, by going beyond looking at the individual competencies and demographics of communicators as well as the time and budget available for E\&M processes.

Specifically, the contextual factors previously discussed have been clustered in four groups. Each cluster is related to the perspective driving how evaluation is undertaken within the internal context. E\&M processes can be affected by multiple factors, such as organizational characteristics, cultural traits, relational attributes and communicative features characterizing the internal context. This paper argues that these factors included in each cluster need to be addressed in order to guarantee effective implementation of E\&M management processes. Figure 1 synthesizes the underlying clusters a) evaluative capacity and history (organizational context); b) evaluative culture and leadership (cultural context); c) stakeholder-evaluator relationship (relational context); d) evaluation communicative network (communicative context).

[Please insert Figure 1 here]

Evaluation capacity and history (organizational context)

Evaluation capacity is the knowledge, behavioural and affective skills that enable employees to think more positively about evaluation (Duffy, 2007; Preskyll and Boyle, 2008; Stockdill et al., 2002). Building evaluation capacity is an essential step for the effective execution of E\&M management processes, because it enables people to embrace systematic enquiry. Systematic enquiry lies in routinely asking questions and seeking answers (Preskill and 
Boyle, 2008). As previously noted, participative and collaborative forms of E\&M are becoming more popular (Patton, 1998). Participation encourages learning, but evaluative capacity needs further strategies if it is to be developed. Dedicated training, technical assistance, written materials, communities of practice, meetings are concrete examples of strategies to teach people how to conduct evaluation (Preskill and Boyle, 2008).

Understanding at what stage in the organizational lifecycle the evaluation process is carried out is pivotal for communication managers. For instance, the needs of a company that wants to evaluate internal communication in the normal course of business will be different from those of a company that experiences a significant process of change to its identity and core values. Accordingly, the evaluation process will depend on the situation in which the organization finds itself and the strategies put in place.

The first action that should be done to devise an effective evaluation management process is to analyse current and past communication activities and processes and the procedures put in place to do that. Neglecting what has already been done, setting a benchmark, is important so that new data can be interpreted. Existing evaluations should be scrutinised by looking at the measures in place without being distracted by the way results are collected. Prior to auditing, it is also advisable to look at case histories and studies from other organizations that involve topics the organization under examination might be interested in. In other words, the evaluator should assess if other organizations have dealt with the same questions at the time of evaluation and what answers have been given in order to build on or move away from their approach.

\section{Evaluative culture \& leadership (cultural context)}

An evaluative culture is a set of "shared and persisting positive beliefs about the value of evaluation to the organization and enduring commitment to evaluation practice and the use of findings among its members" (Preskyll and Boyle, 2008, p. 451). Since any organizational 
culture consists of unwritten and unspoken guidelines on how to get along in an organization and conveys a sense of identity to employees (Mayne, 2008), an evaluative culture is a part of an organizational culture that values evidence-based learning.

Evaluative culture can be characterized as a culture of results (Siddiquee, 2010), a culture of performance (Peters, 2004) and a culture of inquiry (Dana et al., 2002). Marr (2006) makes a distinction between "Command \& Control" vs "Enabled Learning Environment" cultural approaches to evaluation. In "Command \& Control" cultures, the focus is exclusively on the attained outcomes, without any interest in setting up effective learning circles. Such a cultural approach might generate misbehaviours, frustration and fear of results because people are exclusively assessed on results without any learning on how to improve their performance. Conversely, creating an "Enabled Learning Environment" means working on the results to gain insights and seek out new ways of undertaking daily activity.

Leadership has been considered an important topic in the field of management and has a huge literature which cannot be fully considered here, however, evidence indicates that there is a close relationship between leadership style and the effective implementation of E\&M management processes (Obiwuru et al., 2011). Managers can adopt a different leadership style in implementing E\&M management processes depending on whether: others help them to achieve their objectives more efficiently and effectively; results are linked to valued rewards; and, they have the resources needed at their disposal to accomplish the desired aims. The literature distinguishes between transformational and transactional leaders:

"Transformational leaders are likely to be more effective than transactional leaders at inspiring followers to identify with a mission while rallying them to work together to achieve higher performance" (Kahai et al., 2003, p. 500). Communication managers hence need to reflect upon evaluation culture and leadership commitment to E\&M processes. They play a pivotal role in shaping evaluative culture by helping communication staff to engage with 
E\&M management processes and coordinating collective efforts to ensure the right quality of data is collected. If the leaders' commitment to E\&M is high, it indicates that the organization places importance on outcomes and on their use in decision-making. Stakeholder-evaluator relationship (relational context)

Every evaluation represents a nexus in a set of political and social relationships. While developing an evaluation plan, each evaluator should carefully analyse the context of evaluation to determine who the evaluation stakeholders are, what they want, and why they want what they want (Rossi et al., 2003). Stakeholders' expectations about performance are also at the centre of performance measurement research. "Good performance management requires that a manager knows when expectations have been accomplished and is able to demonstrate this. Clear and concrete expectations about the outputs and outcomes to be accomplished enable a manager to do this, and to know how successful a program has been and where improvements are required" (Mayne, 2004, p. 35).

For nurturing effective relationships with those with interests in the programs high quantity contact is vital. in communication E\&M, this concerns specifically top managers and other internal partners. More specifically, Torres et al. (1997) suggest maintaining close contact with stakeholders along the different phases of the evaluation process through ongoing communication, periodic meetings, and informal conversations.

At the same time, the evaluator should prioritize stakeholders since the type of relationships varies depending on the stakeholder considered. Patton (1998) assumes that each evaluation process should point out who will use results. Dissemination of results should be clearly addressed to primary stakeholders (e.g. top managers, collaborators, internal partners) and secondary stakeholders (e.g. journalists, customers, service providers or agencies), by using a language suitable to their concerns and depending on what aim the evaluation has. In terms of the mode of relationships, more and more organizations call for evaluators to work 
collaboratively with stakeholders, by implementing participatory or engaging forms of evaluation (Patton, 1998) and empowerment evaluation models (Fetterman et al., 1996).

\section{Evaluation communicative network (communicative context)}

Evaluation rests on collecting real-time and up-to-date information derived from a variety of sources. For this reason, the evaluator should primarily identify the sources and set up an information network to gather data, providing network members with tools and guidelines to make data usable and reliable. Sustainable E\&M practices require systems, processes, policies, and plans that help embed evaluation work into the way the organization accomplishes its strategic mission and goals (Preskill and Boyle, 2006, p. 444). Currents trends in communication field related to big data, digital transformation and artificial intelligence (Forbes Communication Council, 2018) have posited new challenges to communication departments and practitioners on how data can be analyzed and what technological and organizational infrastructure are needed to strategically convert these insights into actionable decisions.

As noted previously, the identification of metrics in use is one of the main streams of communication research. It is crucial to understand the metrics used by other functions, if, for instance, they are more financial or non-financial related, quantitative or qualitative. It might also be relevant to understand the CEO's satisfaction with E\&M processes employed by other functions. In some cases, management prefers dealing with numbers so the outcomes of the evaluation process should be expressed in numerical terms if possible. In other cases, words are preferred when reporting results (Antonioni, 1996; Waldman et al., 1998). Interestingly, Ferstl and Bruskiewicz (2000) found that, when provided with the same results in a quantitative and then a qualitative format, managers pay more attention to the latter.

\section{CONCLUSIONS, LIMITATIONS AND FUTURE TRENDS}


Evaluation and Measurement (E\&M) is a critical topic of inquiry among communication scholars and practitioners. Considerable research and professional efforts have been addressed so far to discussing what should be measured and which methods should be implemented. Most of the E\&M models seem to carry a positivist imprint, but, in real organizational life, organizations could not have clearly defined aims, sufficient resources, or adequate informative systems to support E\&M management processes.

Our scoping review has shown that evaluation and measurement of strategic communication practices mainly borrow principles from two disciplinary domains: program evaluation and performance measurement. By analyzing the legacy of studies on program evaluation and performance measurement and combining the insights with communication research, we identified multiple contextual factors which impact the execution of an E\&M management process: evaluation questions and measures; evaluation approach and design; role of the evaluator and role of stakeholders; evaluative culture; final reports; information technology support and use of results.

However, strategic communication literature has so far largely neglected to consider contextual factors when exploring barriers as obstacles of E\&M implementation in practices. To fulfill this gap, this article has theorized the contextual factors relevant to the management of the evaluation process. In fact, only a few studies in communication have focused on contextual factors affecting E\&M management process success or failure. Against this background, this article begins to fill an apparent gap by categorizing those factors affecting any E\&M management process into four clusters. Thereby, this article extends current thinking on communication E\&M in three ways. First, it explicitly includes the importance of a fit between the main features of the organizational evaluative environment and the E\&M management process. Second, it explicitly addresses the role of relationships among evaluators and 
evaluation stakeholders. Finally, it explores the role of technology and the use of E\&M results in order to manage reliable and meaningful E\&M management processes.

The findings of this scoping review demonstrate that there are great opportunities for additional research deepening knowledge about the implications of contextual factors within evaluation management processes in the strategic communication area.

For what concerns implications for practice, it is argued that methodological sophistication and scientific rigour are frequently the first elements considered when setting up a plan for measuring communication outcomes. While there is no doubt that these are critical, practitioners should bear in mind that effective evaluation and measurement strategies are built upon factors including organizational, cultural, relational, and communicative ones. Several studies in the field of program evaluation and performance measurement have already evidenced that measurement is not a linear process. But, communication professionals have not yet fully embraced the importance of developing a full awareness of which factors, besides the methodological ones, can influence the effectiveness of an evaluation management process. Hence, it is argued that considering contextual factors, such as the organizational (evaluative capacity and history), cultural (evaluative culture and leadership), relational (stakeholderevaluator relationship), and communicative ones (evaluation communicative network), will help communication managers better deal with stakeholders' expectations of evaluation while at the same time gaining trust in the eyes of those organizational managers demanding that communication activities and programs are evaluated. The absence of empirical data represents the first limitation of the article that future research could address: the contextual factor-based clusters identified need to be tested empirically ideally via qualitative and quantitative case studies. Second, our scoping review has not covered the entire literature about evaluation program, performance measurement and performance management streams of research: future research could enrich the list of contextual factors that could affect the E\&M processes. Since 
our review has focused on examining internal context, future studies could address the analysis of external context by identifying contextual factors that could affect E\&M processes outside the organization.

\section{References}

Amaratunga, D., and Baldry, D. (2002), "Moving from performance measurement to performance management", Facilities, Vol. 20 N 5/6, pp. 217-223.

AMEC (Association for Measurement and Evaluation of Communication). (2017). Integrated evaluation framework. London, UK: Author. Retrieved from http://amecorg.com/amecframework (accessed 21 January 2018)

AMEC (Association for Measurement and Evaluation of Communication). (2015). Barcelona principles 2.0. London, UK: Author. Retrieved from http://amecorg.com/barcelonaprinciples-2-0 (accessed 20 January 2018).

Anderson, F. W., Hadley, L., Rockland, D., and Weiner, M. (2009), Guidelines for setting measurable public relations objectives: An update, Institute for Public Relations, Gainesville, FL

Antonioni, D. (1996), "Designing an effective 360-degree appraisal feedback process", Organizational Dynamics, Vol. 25 No 2, pp. 24-38.

Askew, K., Beverly, M. G., and Jay, M. (2012), “Aligning Collaborative and Culturally Responsive Evaluation Approaches", Evaluation and Program Planning, Vol. 35 No 4, pp. $552-557$.

Baskin, O.W. and Aronoff, C.E. (1988), Public Relations: The Profession and the Practice, W.C. Brown, London. 
Bititci, U. S., Garengo, P., Ates, A., and Nudurupati, S. S. (2015), "Value of maturity models in performance measurement", International journal of production research, Vol. 53 No 10, pp. 3062-3085.

Bowers, D. G., and Franklin, J. L. (2006), “Survey-guided development: Using human resources measurement in organizational change", Organizational Development and Training, Vol. 6, pp. 203-213.

Cooper, D. R., Schindler, P. S., and Sun, J. (2006), Business research methods (Vol. 9), McGraw-Hill Irwin, New York.

Dana, N. F., Silva, D. Y., and Snow-Gerono, J. (2002), "Building a culture of inquiry in a professional development school", Teacher education and practice, Vol. 15 No 4, pp. 7189.

Daymon, C., and Holloway, I. (2010), Qualitative research methods in public relations and marketing communications, Routledge, London.

De Lancer, J., and Holzer, M. (2001), "Promoting the Utilization of Performance Measures in Public Organizations: An Empirical Study of Factors Affecting Adoption and Implementation”, Public Administration Review, Vol. 61 No 6, pp. 693-708.

Douwe P. Flapper, S., Fortuin, L. and Stoop, P.P., 1996, "Towards consistent performance management systems", International Journal of Operations \& Production Management, Vol. 16 No. 7 , pp. 27-37.

Duffy, A. (2007), “A concept analysis of reflective practice: determining its value to nurses", British Journal of Nursing, Vol. 16 No 22, pp. 1400-1407.

Fetterman, D. M., Kaftarian, S. J., and Wandersman, A. (1996), Empowerment evaluation: Knowledge and tools for self-assessment and accountability, Sage, London, UK. 
Ferstl, K. L., and Bruskiewicz, K. T. (2000, August). Self-other agreement and cognitive reactions to multirater feedback, paper presented at 15 th annual conference of the Society of Industrial and Organizational Psychology, New Orleans, LA.

Fitzpatrick, J. L., Sanders, J. R., and Worthen, B. R. (2004), Program evaluation: Alternative approaches and practical guidelines, Allyn Bacon, Boston.

Fleisher C.S. and Mahaffy D. (1997), “A Balanced Scorecard Approach to Public Relations Management", Public Relations Review, Vol. 23 No 2, pp. 117-142.

Forbes Communications Council, (2018), “Seven Communications Trends Worth Knowing About", retrieved from

https://www.forbes.com/sites/forbescommunicationscouncil/2018/07/12/sevencommunications-trends-worth-knowing-about/\#25f001544b19 (accessed 20 March, 2019).

GCS (Government Communication Service), (2016, January), “GCS evaluation framework. London, UK: Cabinet Office, Her Majesty’s Government”, retrieved from https://gcs.civilservice.gov.uk/wp-content/uploads/2015/11/GCS GCS-Evaluationframework_A4-_191115.pdf (accessed 20 February 2018).

Grunig, L. A., Grunig, J. E., and Dozier, D. M. (2002), Excellent public relations and effective organizations, Lawrence Erlbaum Associates, Mahwah, NJ.

Hatry, H.P. (2006), Performance measurement: Getting results. The Urban Institute, London. Institute for Public Relations, (2003), Guidelines for Measuring Effectiveness of PR Programs and Activities, Commission on PR Measurement and Evaluation, Institute for Public Relations, Gainsville, FL.

Jackson, E. T. (2013), Interrogating the theory of change: evaluating impact investing where it matters most, Journal of Sustainable Finance \& Investment, Vol. 3 No 2, pp. 95-110. 
Jensen, A. J., and Sage, A.P. (2000), “A systems management approach for improvement of organizational performance measurement systems", Information Knowledge Systems Management, Vol. 2 No 1, pp. 33-61.

Jin, Y., and Cameron, G. T. (2007), "The effects of threat type and duration on public relations practitioner's cognitive, affective, and conative responses in crisis situations", Journal of Public Relations Research, Vol. 19 No 3, pp. 255-281.

Julian, D. A. (1997), "The utilization of the logic model as a system-level planning and evaluation device", Evaluation and Program Planning, Vol. 20, pp. 251-257.

Kahai, S. S., Sosik, J. J., and Avolio, B. J. (2003), "Effects of leadership style, anonymity, and rewards on creativity-relevant processes and outcomes in an electronic meeting system context", The Leadership Quarterly, Vol. 14 No 4-5, pp. 499-524.

Kellen, V., and Wolf, B. (2003), "Business performance measurement", Information Visualization, Vol. 1 No 312, pp. 1-36.

Kerssens-van Drongelen, I.C. and Fisscher, O.A., 2003, "Ethical dilemmas in performance measurement", Journal of Business Ethics, Vol. 45 No 1-2, pp.51-63.

Knowlton, L., and Phillips, C. (2013), The logic models guidebook: Better strategies for great results (2nd ed.), Sage, Thousand Oaks, CA.

Kravchuk, R. S., and Schack, R. W. (1996), "Designing effective performance-measurement systems under the Government Performance and Results Act of 1993", Public administration review, 348-358.

Lindenmann, W.K. (1997), "Setting minimum standards for measuring public relations effectiveness, Public Relations Review, Vol. 23 No 4, pp. 391-402.

Lynch, R.L., and Cross, K.F. (1991), Measure Up - The Essential Guide to Measuring Business Performance, Mandarin, London. 
Macnamara, J.R. (1997), Research in Public Relations. A review of the use of evaluation and formative research, Public Relations Institute of Australia, Australia.

Macnamara, J.R. (1999), "Research in public relations: A review of the use of evaluation and formative research", Asia Pacific Public Relations Journal, Vol. 1 No 2, pp. 107-133.

Macnamara, J.R. (2014), “The 'toe bone to the head bone' logic model to connect public relations and corporate communication to organization outcomes", Prism, Vol 11 No 1.

Macnamara, J.R. (2015), "Breaking the measurement and evaluation deadlock: a new approach and model”, Journal of Communication Management, Vol. 19 No 4, pp. 371-387.

Macnamara, J.R. (2018a). Evaluating public communication: Exploring new models, standards, and best practice. Routledge, Abingdon, UK.

Macnamara, J.R. (2018b), “A review of new evaluation models for strategic communication: Progress and gaps”, International Journal of Strategic Communication, Vol. 12 No 2, pp. $180-195$.

Macnamara, J.R. and Likely, F. (2017) "Revisiting the disciplinary home of evaluation: New perspectives to inform PR evaluation standards", Research Journal of the Institute for Public Relations.

Mayne, J. (2004), "Reporting on outcomes: Setting performance expectations and telling performance stories", The Canadian Journal of Program Evaluation, Vol. 19 No 1, p. 31.

Mayne, J. (2008), "Building an evaluative culture for effective evaluation and results management”, ILAC Brief, Vol. 20.

Marr, B. (2006), Strategic performance management - Leveraging and measuring your intangible value drivers, Butterworth-Heinemann, Oxford.

Maskell, B. (1989), "Performance measurement for world class manufacturing", Management Accounting, May, pp. 32-3 
Mattila, A. S. (1999), "The role of culture in the service evaluation process", Journal of service research, Vol. 1 No 3, pp. 250-261.

McDavid, J.C., and Hawthorn, L.R.L. (2006), Program evaluation and performance measurement: An introduction to practice, Sage Publications, Thousand Oaks, CA.

McDavid, J. C., Huse, I., Hawthorn, L. R., and Ingleson, L. R. (2012), Program evaluation and performance measurement. Sage, London.

McLaughlin, J. A., and Jordan, G. B. (2004), “Using logic models”, in K. E. Newcomer, H. P. Hatry and J. S. Wholey (Eds.), Handbook of practical program evaluation, John Wiley \& Sons, Hoboko, NJ (pp. 7-32).

Morgan, D. L. (2007), "Paradigms lost and pragmatism regained: Methodological implications of combining qualitative and quantitative methods", Journal of mixed methods research, Vol. 1 No 1, pp. 48-76.

Neely, A. (2005), “The evolution of performance measurement research: developments in the last decade and a research agenda for the next", International Journal of Operations \& Production Management, Vol. 25 No 12, pp. 1264-1277.

Neely, A.D., Mills, J.F., Gregory, M.J., Richards, A. H., Platts, K.W. and Bourne, M.C.S. (1996), Getting the Measure of your Business, Findlay, London.

Neely, A., Mills, J., Platts, K., Richards, H., Gregory, M., Bourne, M. and Kennerley, M., (2000), "Performance measurement system design: developing and testing a process-based approach", International journal of operations \& production management, Vol. 20 No 10, pp.1119-1145.

Obiwuru, T. C., Okwu, A. T., Akpa, V. O., and Nwankwere, I. A. (2011), “Effects of leadership style on organizational performance: A survey of selected small scale enterprises in IkosiKetu council development area of Lagos State, Nigeria" Australian journal of business and management research, Vol. 1 No 7, p. 100. 
Paine, K.D. (2007), Measuring Public Relationships. KD Paine \& Partners, Berlin (NH).

Parmenter, D. (2007), Key Performance Indicators (KPI): Developing, Implementing and Using winning KPIs, Wiley-Blackwell, London (UK).

Patton, M.Q. (1998). Utilization-focused evaluation. Sage, Beverly Hills (CA).

Pawson, R., and Tilley, N. (1997). Realistic Evaluation. Sage, London (UK).

Peters, M.A. (2004), “'Performative','Perfomativity'and the Culture of Performance: knowledge management in the new economy (Part 2)", Management in Education, Vol. 18 No 2, pp. 20-24.

Preskill, H., and Boyle, S. (2008), “A multidisciplinary model of evaluation capacity building”, American journal of evaluation, Vol. 29 No 4, pp. 443-459.

Ritchie, J. (2003), “The applications of qualitative methods to social research", in Ritchie J., Lewis, J (Eds.), Qualitative research practice: A guide for social science students and researchers, Sage, London (UK), pp. 24-47.

Ritter, M. (2003), “The Use of Balanced Scorecards in the Strategic Management of Corporate Communication", Corporate Communications: an International Journal, Vol. 8 No 1, pp. 44-59.

Rossi, P.H., Lipsey, M.W., and Freeman, H.E. (2003), Evaluation: A systematic approach. Sage, London (UK).

Sachs, I. (2011), Performance Driven IT Management: Five Practical Steps to Business Success, Government Institute, Playmuth, (UK).

Scriven, M. (1996), “Types of evaluation and types of evaluator, Evaluation Practice, Vol. 17 No 2, pp. 151-161.

Senge, P. M. (1991), "The fifth discipline, the art and practice of the learning organization", Performance+ Instruction, Vol. 30 No 5, pp. 37-37. 
Siddiquee, N. (2010), "Managing for results: lessons from public management reform in Malaysia”, International Journal of Public Sector Management, Vol. 23 No 1, pp. 38-53.

Simon, H. A. (1991), "Bounded rationality and organizational learning", Organization science, Vol. 2 No 1, pp. 125-134.

Sonenshein, S. (2010), "We're Changing-Or are we? Untangling the role of progressive, regressive, and stability narratives during strategic change implementation", Academy of Management Journal, Vol. 53 No 3, pp. 477-512.

Stockdill, S. H., Baizerman, M., and Compton, D. W. (2002), “Toward a definition of the ECB process: A conversation with the ECB literature", New Directions for Evaluation, Vol. 2002 No 93, pp. 7-25.

Swenson, R., Gilkerson, N., Likely, F., Anderson, F. W., and Ziviani, M. (2019), "Insights from Industry Leaders: A Maturity Model for Strengthening Communication Measurement and Evaluation", International Journal of Strategic Communication, Vol. 13 No 1, pp. 121.

Torres, R. T., Preskill, H. S., and Piontek, M. E. (1997), "Communicating and reporting: Practices and concerns of internal and external evaluators", Evaluation Practice, Vol. 18 No 2, pp. 105-125.

Volk, S. C. (2016), “A systematic review of 40 years of public relations evaluation and measurement research: Looking into the past, the present, and future", Public Relations Review, Vol. 42 No 5, pp. 962-977.

Vos, M., and Schoemaker, H. (2004, July), Accountability of Communication policy, paper presented at Bledcom, Bled, Slovenia.

Waldman, D. A., Atwater, L. E., and Antonioni, D. (1998), "Has 360 degree feedback gone amok?", The Academy of Management Executive, Vol. 12 No 2, pp. 86-94. 
Watson T. (2001), "Integrating Planning and Evaluation: Evaluating the Public Relations Practice and Public Relations Programs", in Heat R. (edited by) (2001), Handbook of Public Relations, Sage, Thousand Oaks.

Watson, T. (2012), "The evolution of public relations measurement and evaluation", Public Relations Review, Vol. 38 No 3, pp. 390-398.

Watson, T., and Likely, F. (2013). "Measuring the Edifice: Public Relations Measurement and Evaluation Practices Over the Course of 40 Years", In Sriramesh, K., Zerfass, A. and Kim, J.N. (eds.), Public Relations and Communication Management, Routledge, New York, pp. 183-202.

Weiss, C.H. (1972), Evaluation research. Methods for assessing program effectiveness, Englewood Cliffs, New Jersey.

Weiss, C. H. (1997), “Theory-based evaluation: Past, present, and future”, New directions for evaluation, Vol. 76, pp. 41-55.

Weiss, C.H., and Bucuvalas M.J. (1980), Social Science Research and Decision-making, Columbia University Press, New York.

Wettstein, T. and Kueng, P. (2002), "A maturity model for performance measurement systems", WIT Transactions on Information and Communication Technologies, Vol. 26.

Winsted, K. F. (1999), "Evaluating service encounters: A cross-cultural and cross-industry exploration", Journal of Marketing Theory and Practice, Vol. 7 No 2, pp. 106-123.

Zerfass, A. (2010), “Assuring rationality and transparency in corporate communications. Theoretical foundations and empirical findings on communication controlling and communication performance management" in Ethical issues for public relations practice in a multicultural world, 13th International Public Relations Research Conference, pp. 947966. 
Zerfass, A., Verčič, D., and Volk, S. C. (2017), “Communication evaluation and measurement: Skills, practices and utilization in European organizations", Corporate Communications: An International Journal, Vol. 22 No. 1, pp. 2-18. 
Table 1. Comparison between the role of contextual factors in Program Evaluation and Performance Measurement studies

\begin{tabular}{|c|c|c|}
\hline Contextual factors & $\begin{array}{l}\text { Program Evaluation } \\
\text { Literature }\end{array}$ & $\begin{array}{l}\text { Performance Measurement } \\
\text { Literature }\end{array}$ \\
\hline $\begin{array}{l}\text { 1. Evaluation questions \& } \\
\text { measures }\end{array}$ & $\begin{array}{l}\text { Questions emerge from } \\
\text { stakeholder interests at one } \\
\text { point in time (issue specific) } \\
\text { (Pawson and Tilley, 1997; Scriven, } \\
\text { 1996) }\end{array}$ & $\begin{array}{l}\text { Routinised, concerning } \\
\text { general management issues } \\
\text { (McDavid et al., 2012; Lynch and } \\
\text { Cross, 1991; Maskell, 1989; Neely et } \\
\text { al., 1996) }\end{array}$ \\
\hline $\begin{array}{l}\text { 2. Evaluation approach \& } \\
\text { design }\end{array}$ & $\begin{array}{l}\text { Selected at the beginning of } \\
\text { the process and driven by ad } \\
\text { hoc needs on communication } \\
\text { projects } \\
\text { (Weiss and Bucuvalas, 1980; } \\
\text { Fetterman et al., 1996; Morgan, 2007; } \\
\text { Rossi et al., 2003) }\end{array}$ & $\begin{array}{l}\text { Assumed, measurement is a } \\
\text { routine; designed for } \\
\text { providing regular information } \\
\text { for organization } \\
\text { (Neely et al., 2000) }\end{array}$ \\
\hline 3. Role of evaluator & $\begin{array}{l}\text { Evaluator as an external } \\
\text { auditor } \\
\text { (Patton, 1998) }\end{array}$ & $\begin{array}{l}\text { Managers are evaluators } \\
\text { (Kerssens-Van Drongelen and Fisscher, } \\
\text { 2003) }\end{array}$ \\
\hline 4. Role of stakeholders & $\begin{array}{l}\text { Collaborative, empowering, } \\
\text { participatory } \\
\text { (Fetterman et al., 1996; Askew et al., } \\
\text { 2012) }\end{array}$ & $\begin{array}{l}\text { Results are shared among } \\
\text { evaluation stakeholders } \\
\text { (Band, 1990) }\end{array}$ \\
\hline 5. Evaluative culture & $\begin{array}{l}\text { Evaluator should analyse } \\
\text { evaluation culture } \\
\text { (Julian, 1997; Jackson, 2013; Mayne, } \\
\text { 2008) }\end{array}$ & $\begin{array}{l}\text { Aligned between } \\
\text { measurement and } \\
\text { organizational systems } \\
\text { (Neely, 2005; Bititci et al., 2015; } \\
\text { Mattila, 1999; Winstead, 1999; } \\
\text { Kravchuck and Schack, 1996)) }\end{array}$ \\
\hline 6. Final reports & $\begin{array}{l}\text { Reports are customized } \\
\text { (McDavid and Hawthorn, 2006; } \\
\text { Macnamara and Likely, 2017; } \\
\text { Knowlton and Phillips, 2013) }\end{array}$ & $\begin{array}{l}\text { Reports are developed } \\
\text { through routinized processes } \\
\text { (Douwe et al., 1996) }\end{array}$ \\
\hline $\begin{array}{l}\text { 7. Information } \\
\text { Technology support }\end{array}$ & $\begin{array}{l}\text { Seldom used, tailored to the } \\
\text { project evaluated } \\
\text { (McDavid and Hawthorn, 2006; } \\
\text { Macnamara and Likely, 2017; } \\
\text { Knowlton and Phillips, 2013) }\end{array}$ & $\begin{array}{l}\text { Relied on IT procedures for } \\
\text { ongoing collection of data } \\
\text { (Wettstein and Kueng, 2002) }\end{array}$ \\
\hline 8. Uses of results & $\begin{array}{l}\text { Uses are usually negotiated } \\
\text { up front } \\
\text { (McDavid and Hawthorn, 2006; } \\
\text { Macnamara and Likely, 2017; } \\
\text { Knowlton and Phillips, 2013) } \\
\end{array}$ & $\begin{array}{l}\text { Uses evolve over time due to } \\
\text { management's needs } \\
\text { (Hatry, 2006) }\end{array}$ \\
\hline
\end{tabular}


Figure 1. Clusters of contextual factors for an effective E\&M Management Process

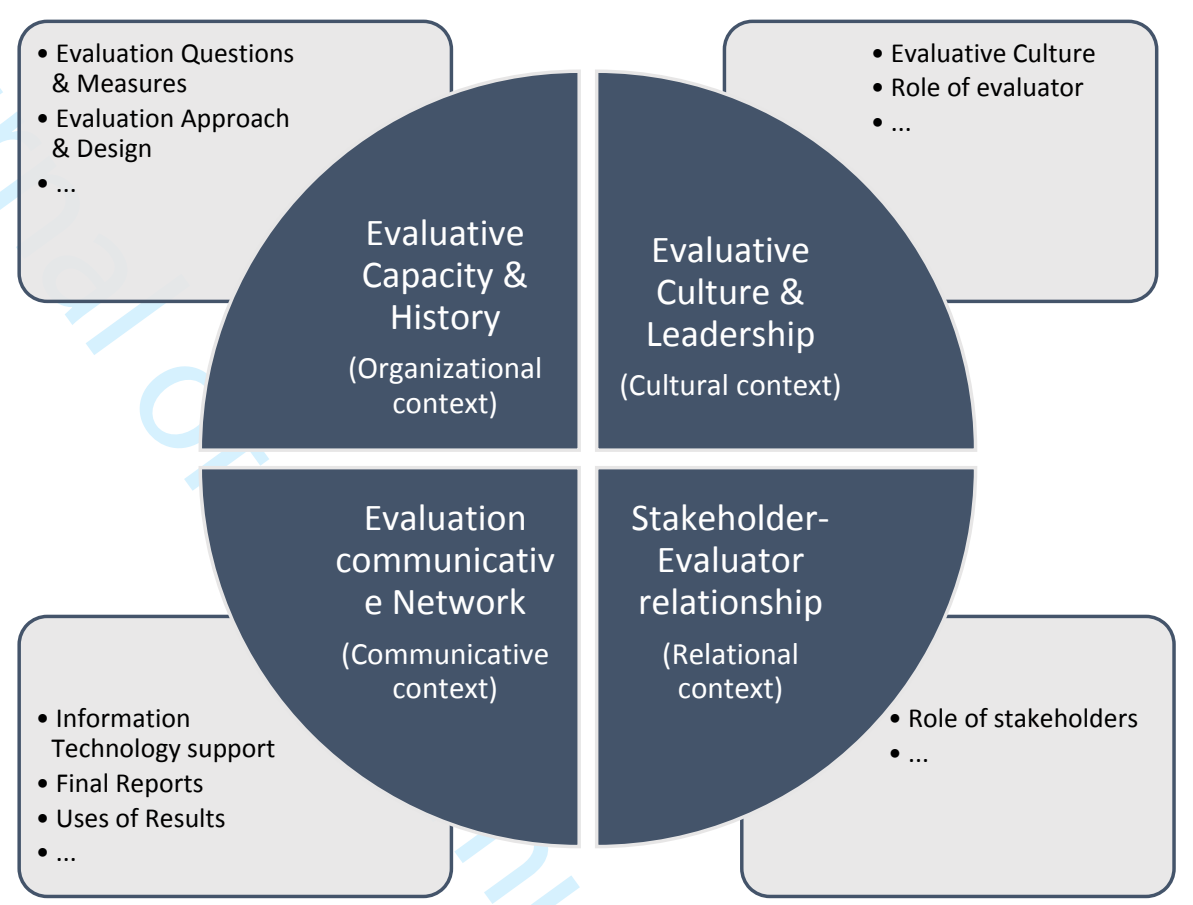

